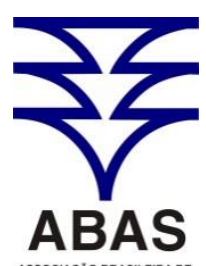

ASSOCIACÁA BRASILEIRADE
AGUAS SUBTERRANEAS www.abas.org

\title{
USO DE GEOTECNOLOGIAS NA AVALIAÇÃO DA FAVORABILIDADE HIDROGEOLÓGICA EM AQQUÍFEROS FRATURADOS
}

\author{
USE OF GEOTECHNOLOGIES IN THE EVALUATION OF \\ HYDROGEOLOGICAL FAVORABILITY IN FRACTURED AQUIFER
}

\author{
Joaquim Ernesto Bernardes Ayer ${ }^{1}$; Danilo Francisco Trovo Garofalo ${ }^{2}$; \\ Sueli Yoshinaga Pereira ${ }^{3}$
}

Artigo recebido em: 12/12/2016 e Aceito para publicação em: 15/05/2017.

DOI: http://dx.doi.org/10.14295/ras.v31i3.28773

\begin{abstract}
Resumo: Este artigo trata do mapeamento da favorabilidade hidrogeológica em aquíferos fraturados, na região do Circuito das Águas Paulista. As técnicas de sensoriamento remoto e análise geoespacial foram utilizadas para criação e combinação de mapas geológico, fisiográficos, estrutural, de uso e cobertura do solo e de favorabilidade. Estes dados foram manipulados em sistemas de informação geográfica, visando ao mapeamento da favorabilidade hidrogeológica, utilizando lógica Fuzzy. O mapeamento de favorabilidade se mostrou de acordo com os valores de capacidade específica, e com o padrão de distribuição dos poços. Além disso, a superfície de tendência gerada a partir dos dados de capacidade específica se mostrou em conformidade com o mapa de favorabilidade, corroborando a acurácia do método utilizado e demonstrando uma alta favorabilidade hidrogeológica nos municípios e Águas de Lindóia de Lindóia.
\end{abstract}

Palavras Chaves: Lógica Fuzzy. Análise Geoespacial. Potencial hidrogeológico. Circuito das Águas Paulista.

\begin{abstract}
This article deals with the mapping of hydrogeological favorability in fractured aquifers, in the so called Circuito das Águas Paulista. Remote sensing and geospatial analysis techniques were used to create and combine geological, physiographic, structural, land cover, and favorability maps. These data were manipulated in geographic information systems, aiming the mapping of hydrogeological favorability, using Fuzzy logic. The favorability mapping was shown according to the specific capacity values and to the distribution pattern of the wells. In addition, the trend surface generated from the specific capacity data was in accordance with the favorability map, corroborating the accuracy of the applied method, showing a high hydrogeological favorability in the Águas de Lindóia and Lindóia municipalities.
\end{abstract}

Keywords: Fuzzy Logic. Geospatial Analysis. Hydrogeological Potential. Circuito das Águas Paulista.

\section{INTRODUÇÃO}

A crise hídrica que assolou o sudeste do Brasil a partir do ano de 2014 e a deterioração das águas superficiais são fatores que têm aumentado a pressão sobre a exploração das águas subterrâneas no país. De acordo com Tundisi et al. (2014), a média atual de perfurações de poços outorgados no Brasil é de 10.800 por ano. Contudo, há ainda pouco conhecimento da hidrodinâmica dos aquíferos no Brasil, e de acordo com Hirata et al. (2010), a principal deficiência para gestão adequada dos aquíferos subterrâneos no Brasil é a carência de dados básicos sobre a favorabilidade hídrica e seu potencial de exploração, o que dificulta a elaboração de planos de gestão atual e futura.

Neste contexto, técnicas de sensoriamento remoto e de geoprocessamento

1 Faculdade de Paulinia - FACP. E-mail: (joaquimayer@ige.unicamp.br)

2-3 Universidade Estadual de Campinas (Unicamp), Campinas, SP. E-mails: (danilogarofalo@ige.unicamp.br; sueliyoshinaga@gmail.com) 
se configuram como importantes instrumentos na identificação, conservação e fiscalização dos recursos hídricos subterrâneos. A avaliação e modelagem destes recursos têm sido feita com sucesso desde a década de 1970, porém, atualmente, o uso de recursos digitais, conjuntamente à análise geoespacial, tem permitido um melhor tratamento e espacialização de dados (FETTER, 1994; FEITOSA, 2008, OH et al., 2011; ABDALLA, 2012; ELBEIH, 2015; OIKONOMIDIS, 2015; RAHMATI et al, 2016).

O uso destes métodos na identificação dos condicionantes naturais que regulam a distribuição e qualidade destes recursos possibilita seu aproveitamento mais racional. Existem teorias tradicionais para avaliação da favorabilidade em aquíferos fissurais, como o critério do riacho fenda (lineamentos) e dos aluviões (depósitos de sedimentos), porém estes dependem muito da experiência do responsável pela perfuração do poço tubular, e não tem aplicação na gestão (FEITOSA, 2008). Já o desenvolvimento de métodos computacionais para avaliação da favorabilidade à água subterrânea em aquíferos fissurais contribui com uma avaliação mais precisa e detalhada sobre a área de interesse permitindo eficiência na explotação deste recurso (SMERDON et al., 2009; SOUZA FILHO et al., 2010; ABDALLA, 2012; ELBEIH, 2015; RAHMATI et al, 2016).

De tal modo, para avaliar a favorabilidade hidrogeológica, é necessário definir quais parâmetros são mais adequados às especificidades locais e que melhor representam as características fisiográficas dominantes no condicionamento do potencial hidrogeológico. Os modelos hidrogeológicos conceituais em áreas fissurais têm utilizado uma ampla quantidade de variáveis, devido à complexidade da evolução tectônica e geomorfológica destas áreas. Na maioria dos casos, os parâmetros são estabelecidos a partir da correlação entre a produtividade dos poços com distintas configurações da paisagem. Assim, os principais métodos conceituais utilizam caraterísticas que favoreçam a porosidade secundária ou primária, como litotipos, lineamentos e morfoestruturas, zonas de juntas e de camadas, dissecação do relevo, pedologia, vegetação e manto de intemperismo, entre outras, para avaliar a favorabilidade (SMERDON et al., 2009; SOUZA FILHO et al., 2010; OH et al., 2011; OIKONOMIDIS, 2015).

Neste contexto, o uso de ferramentas computacionais e geoestatísticas possibilita avaliar de forma sistêmica o ambiente e calcular estes elementos, devido às facilidades da análise espacial em Sistemas de Informação Geográfica (SIG), onde os dados podem ser manipulados a partir de princípios geoestatísticos de inserção (hierarquias), justaposição (proximidade / contiguidade) e funcionalidade (causalidade) numa análise sistêmica e integrada (HUGGET, 1980).

Vale destacar que o Estado de São Paulo é o maior produtor nacional de água mineral, com $17 \%$ da produção, sendo que a região do Circuito das Águas Paulista responde por $30 \%$ desta produção (DNPM, 2013) e é estratégica, tendo em vista a proximidade dos maiores centros consumidores do Brasil. Esta região é dependente economicamente da exploração da água, seja de maneira direta no envasamento de água mineral, ou de forma indireta, como atrativo turístico, o que justifica o estudo. De tal modo, modelos conceituais hidrogeológicos, possibilitam mostrar áreas com bom potencial para explotação de águas subterrâneas em aquíferos cristalinos e são indicados para gestão e utilização destes recursos.

Dentro desta perspectiva, este trabalho objetivou avaliar a favorabilidade hidrogeológica na região do Circuito das Águas Paulista (municípios de Águas de Lindóia e Lindóia), com aplicação de um método baseado em análise geoespacial. $\mathrm{O}$ método utilizado é de fácil aplicação para avaliação de aquíferos fissurais e é útil aos gestores públicos e privados. Em virtude disto, foram adquiridos dados fisiográficos da paisagem para calcular e espacializar a favorabilidade hidrogeológica da área, utilizando lógica Fuzzy. 
2 CARACTERIZAÇÃO DA ÁREA DE
ESTUDO

A área de estudo compreende os $\mathrm{Mu}$ - nicípios de Águas de Lindóia e Lindóia (Figura 1), localizados no Circuito das Águas Paulista. Segundo a classificação de Köppen, a região está sob o domínio climático Tropical Mesotérmico, também denominado Tropical de Altitude (Cwa) (SPAROVEK et al., 2007).

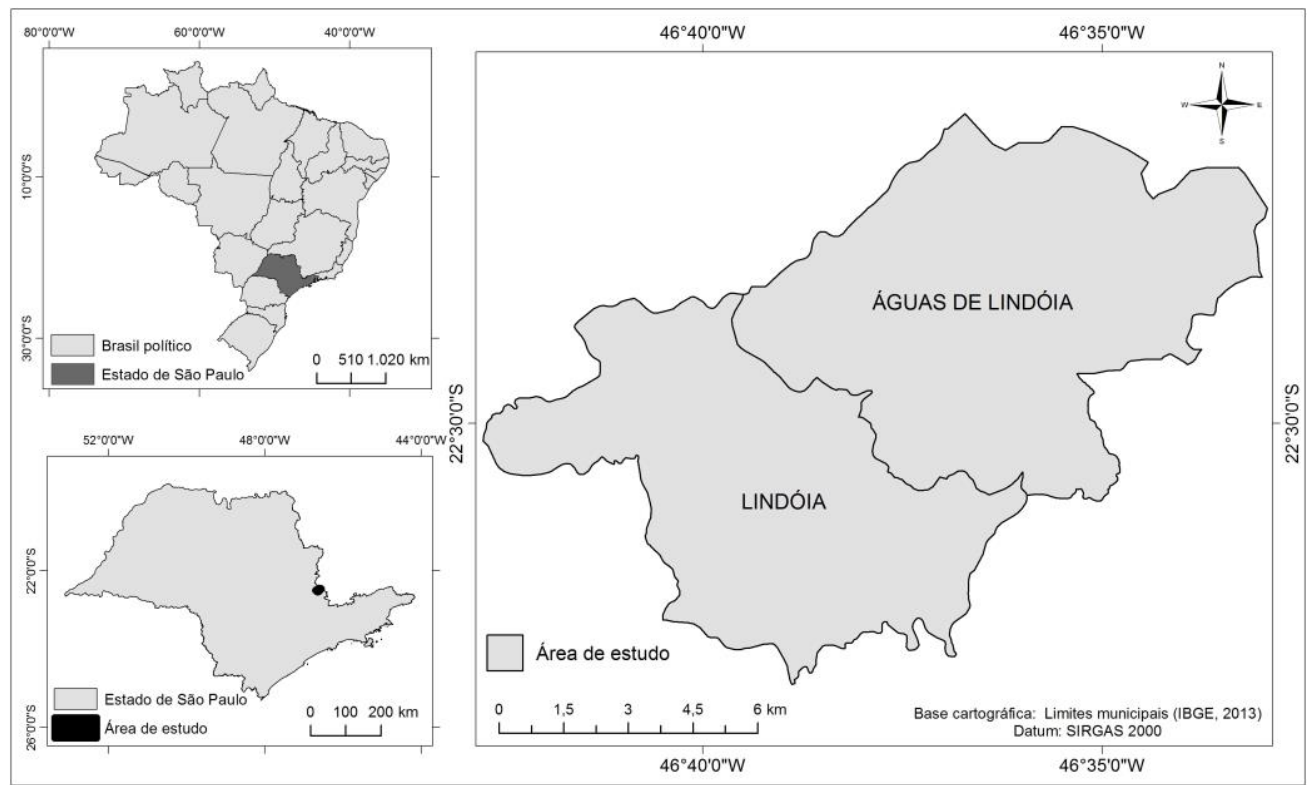

Figura 1 - Mapa de localização dos municípios de Lindóia e Águas de Lindóia

Figure 1 - Location map of the study area

A altitude varia de 641 a $1.311 \mathrm{~m} \mathrm{em}$ relação ao nível do mar (Figura 2a), com declives/aclives entre $0^{\circ}$ e $33^{\circ}$ (Figura 3) e taxa de precipitação anual entre 1.140 e 2.020 $\mathrm{mm}$. A porção norte-noroeste da área é onde se encontram as maiores altitudes, diminuindo suavemente na direção nordeste. Na porção sul, destaca-se o vale do Rio do Peixe, de menores altitudes (Figura 2a). As superfícies mais declivosas cortam a área de noroeste a sudoeste (Figura 2b). Os municípios estão inseridos no domínio do bioma Mata Atlântica (SOSMA, 2013).

A área está localizada na porção central da província da Mantiqueira e é constituída predominantemente por rochas antigas que foram afetadas por múltiplos ciclos e fases metamórficas, eventos que atuaram desde o Arqueano até o Proterozóico Superior (ALMEIDA \& HASUI, 1984).

As rochas mais antigas pertencem ao Grupo Amparo - migmatíticas, gnáissicas e graníticas - e as rochas gnáissicas e metassedimentares, como quartzitos e ortoquartzitos, pertencem ao Complexo Itapira e são extremamente fraturadas, o que favorece a circulação de água subterrânea (Figura 3). As rochas da área investigada apresentam, principalmente, os seguintes constituintes minerais: plagioclásios, ortoclásio, biotita, hornblenda e muscovita (ALMEIDA \& HASUI, 1984; YOSHINAGA, 1990; MADRUCCI et al., 2008; HASUI, 2010). 


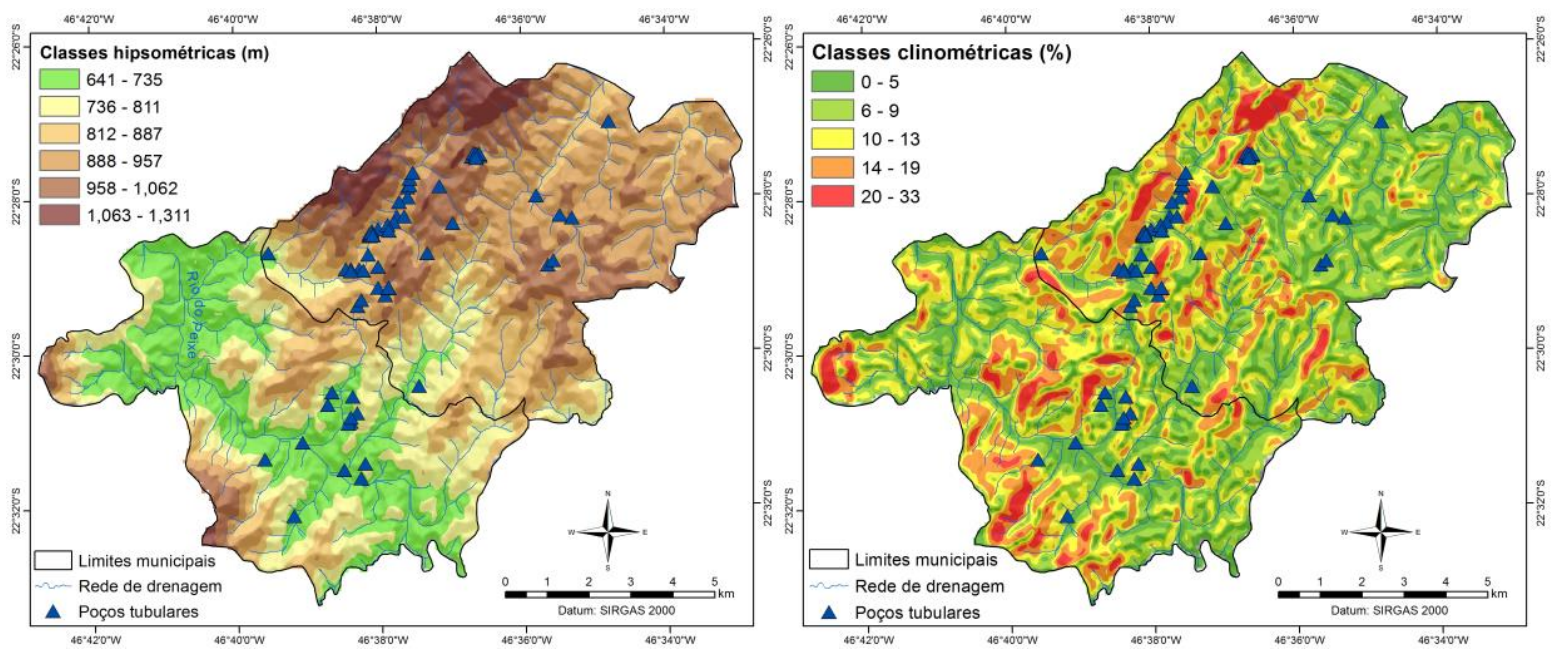

Figura 2 - (a) Mapa hipsométrico; (b) Mapa clinométrico da área de estudo

Figure 2 - (a) Hypsometric map; (b) Clinometric map of the study area

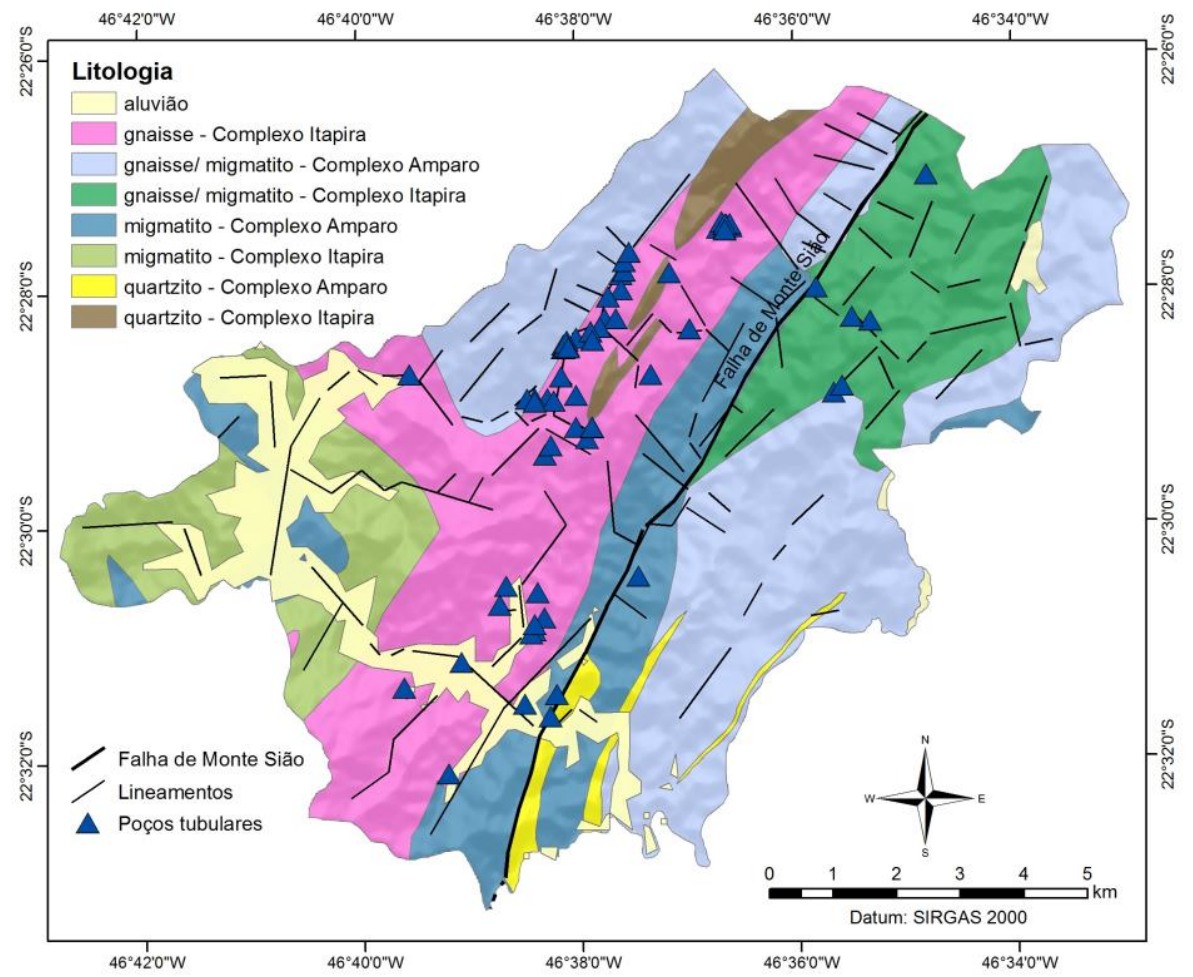

Figura 3 - Mapa de síntese da geologia da área de estudo (modificado de Madrucci et al, 2008) Figure 3 - Map of the geology synthesis (modified from Madrucci et al, 2008)

Segundo Yoshinaga (1990), nos dois municípios, as águas subterrâneas apresentam baixa mineralização, $\mathrm{pH}$ predominante ácido, mas com áreas em que são neutras a ligeiramente básicas (entre 4,47 e 7,38), onde as águas das chuvas, poços e fontes em geral, possuem as seguintes concentrações de íons prinicipais (meq/l): $\mathrm{rCa}>\mathrm{rMg}>\mathrm{rK}$ e $\mathrm{r} \mathrm{HCO}_{3}$ $>\mathrm{rCl} \approx \mathrm{rNO}_{3}>\mathrm{rSO}_{4}$ e são classificadas em sua maioria como bicarbonatadas cálcicas e bicarbonatadas cálcio-magnesianas.

\section{MATERIAIS E MÉTODOS}

O método utilizado neste trabalho tem como base conceitual a teoria geral dos sistemas (BERTALANFFY, 1932; CHORLEY e KENNEDY, 1971; HUGGET, 
1980). Seguindo esta teoria, trabalhou-se com a hipótese de que a favorabilidade hidrogeológica (variável dependente) de uma determinada área é decorrente de suas características fisiográficas (variáveis independentes), que condicionam o armazenamento e transmissão das águas subterrâneas.

A base cartográfica utilizada, composta por produtos de sensoriamento remoto e arquivos vetoriais, está descrita na Tabela 1. Foram utilizados ainda, dados de capacidade específica de 78 poços tubulares, para a validação e discussão dos resultados de favorabilidade hidrogeológica. Vale destacar que a maioria destes poços foram perfurados pelo método de percussão e apresentam revestimento liso de aço com diâmetros iniciais entre 8" e 10". Apenas alguns possuem filtros, uma vez que a perfuração em rochas cristalinas segue as especificações técnicas ditadas pelo Departamento Nacional de Produção Mineral - DNPM. A profundidade dos poços varia de cerca de 49 a $300 \mathrm{~m}$ com média de $100 \mathrm{~m}$, onde os poços mais profundos apresentam menores vazões (Yoshinaga,1990; DAEE, 2016).

Tabela 1 - Materiais cartográficos utilizados

Table 1-Cartographic materials used

\begin{tabular}{|c|c|c|c|c|}
\hline Plano de informação & $\begin{array}{l}\text { Folha / } \\
\text { Arquivo }\end{array}$ & $\begin{array}{l}\text { Escala/ } \\
\text { resolução }\end{array}$ & Formato & Autoria \\
\hline Rede hidrográfica & Rede de drenagem do Estado de São Paulo & $1: 100.000$ & Vetorial - .shp & DAEE, 2008 \\
\hline Limites municipais & Malha digital dos municípios de São Paulo & $1: 50.000$ & Vetorial - .shp & IBGE, 2015 \\
\hline Litologia & $\begin{array}{c}\text { Mapa geológico do Circuito das Águas } \\
\text { Paulista }\end{array}$ & $1: 50.000$ & Vetorial - .shp & Madrucci, 2008 \\
\hline Altimetria & MDE Topodata, cena 22S48_ZN & $30 \mathrm{~m}$ & Matricial - .tif & INPE, 2010 \\
\hline Forma do terreno & $\begin{array}{c}\text { Cena 22S48_FT derivada do MDE } \\
\text { Topodata }\end{array}$ & $30 \mathrm{~m}$ & Matricial - .tif & INPE, 2010 \\
\hline $\begin{array}{l}\text { Cobertura vegetal e uso } \\
\text { do solo }\end{array}$ & $\begin{array}{l}\text { Imagens do sensor OLI do satélite Landsat } \\
8 \text {, órbita/ponto } 219 / 76-04 / 05 / 2015\end{array}$ & $30 \mathrm{~m}$ & Matricial - .tif & NASA, 2016 \\
\hline
\end{tabular}

Com relação à operacionalização da pesquisa, todo o processamento das imagens e análises foram conduzidos no software ArcGIS 10.5 (ESRI, 2016).

Os procedimentos metodológicos aplicados na análise do potencial hidrogeológico foram divididos em quatro etapas principais, conforme descrito abaixo.

\subsection{Mapeamento de variáveis biofisio- gráficas}

$\underline{\text { Litologia }}$

O mapa litológico foi modificado de MADRUCCI (2008), sendo que a este foram adicionados os lineamentos demarcados nesta pesquisa, e foram identificadas as áreas de deposição hidrossedimentológica ou aluviões. Para identificação destas áreas foi utilizado o MDE Topodata. Utilizando a ferramenta Raster Calculator, foram extraídas as áreas com altitude inferior a 700 metros, nível de base local. Destas áreas foram, por sua vez, extraídas as áreas com declives menores do que $3 \%$ em várzea, que normalmente favorecem a deposição de sedimentos. Posteriormente, estas áreas foram checadas a partir da imagem do Google Earth Pro, para avaliar se havia correspondência destes locais com as feições geomorfológicas de depósitos de aluvião.

Densidade de lineamentos morfoestruturas e densidade de drenagem

A identificação dos lineamentos morfoestruturais tomou como base cartográfica o arquivo vetorial da rede de drenagem (arquivo vetorial da rede de drenagem do Estado de São Paulo - DAEE, 2008) e o arquivo raster do relevo sombreado (Cena 22S48_RS do projeto Topodata Valeriano et al., 2010). Os lineamentos morfoestruturais foram traçados por meio de interpretação visual da drenagem e dos elementos texturais do relevo, com ênfase nas quebras negativas de relevo (fundo de vale) e 
na estruturação da rede de drenagem, conforme proposto por Soares \& Fiori (1976). A interpretação da rede de drenagem em conjunto com a imagem de sombreamento do relevo originou um arquivo vetorial composto por 122 traços de lineamentos morfoestruturais.

A densidade de lineamentos morfoestruturais e de drenagem foi calculada e espacializada por meio da ferramenta Kernel Density da extensão Spatial Analyst Tools do software ArcGIS 10.5. A ferramenta Kernel Density realiza uma contagem de todos elementos (lineamentos e canais de drenagem) dentro de um raio de abrangência, ponderando-os pela distância de cada um à localização de interesse (CARVALHO e CÂMARA, 2004). Os arquivos raster resultantes (extensão de lineamentos $/ \mathrm{km}^{2}$ e extensão de drenagem $/ \mathrm{km}^{2}$ ) foram classificados em cinco classes pelo método de classificação Quebras Naturais.

\section{Clinometria e Forma do terreno}

O mapeamento clinométrico (declive/aclive), tomou como base o MDE Topodata, já recortado conforme os limites da área de estudo. A clinometria foi calculada em porcentagem a partir do comando Slope do módulo Surface do software ArcGIS 10.5. O mapa clinométrico foi subdividido em cinco classes, com emprego do método de classificação Quebras Naturais, que tende a dividir as classes nas áreas de maior variância entre os valores. Com relação ao mapa de Forma do Relevo, fez-se o recorte do arquivo 22S48_FT com os limites da área de estudo. A imagem de Forma do Terreno disponibilizada por Valeriano et al. (2010) apresenta nove classes de forma, conforme ilustrado na Figura 4.

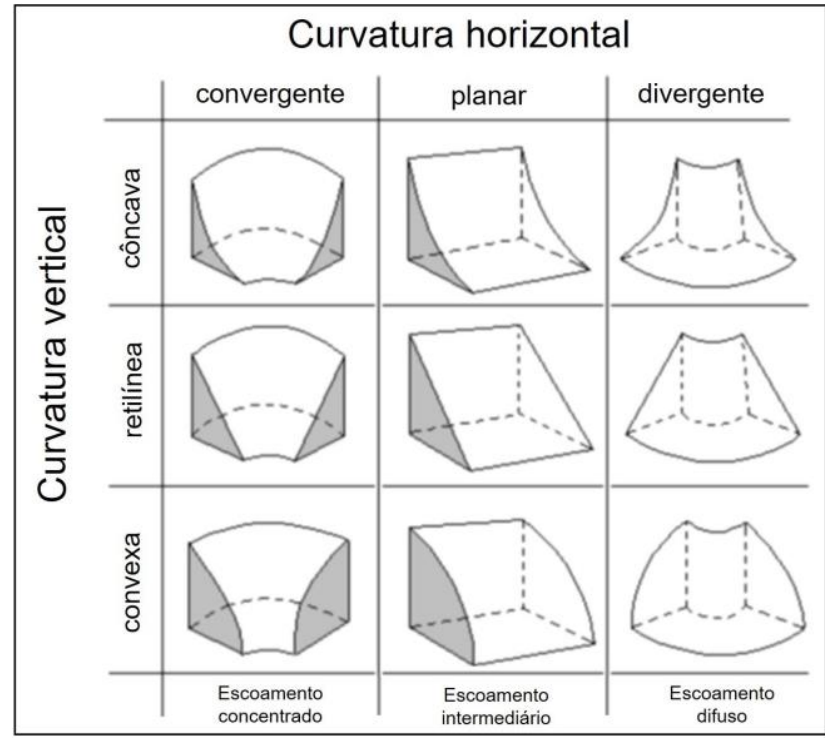

Figura 4 - Classes de Forma do Terreno

Fonte: Modificado de Dikau (1990) apud Valeriano et al. (2008)

Figure 4 - Land Shape Classes

Fonte: Modified de Dikau (1990) apud Valeriano et al. (2008)

\section{$\underline{\text { Uso e cobertura do solo }}$}

O mapa de uso e cobertura do solo foi derivado das bandas multiespectrais do sensor OLI do satélite Landsat 8, órbita/ponto 219/76 - 04/05/2016. Inicialmente, as bandas multiespectrais (bandas espectrais de 1 a 7 ) foram recortadas, conforme os limites políticos dos municípios em análise. Posteriormente, foi realizado o empilhamento das sete bandas multiespectrais, a partir da ferramenta CompositeBands, tendo como resultado um arquivo composto pelas sete bandas. 
Com base no arquivo supracitado em uma composição falsa-cor (R5G4B3), foram definidas sete classes de uso e cobertura do solo: remanescentes florestais; silvicultura; pastagem e campo sujo; cultivos agrícolas; solo exposto; áreas urbanas, chácaras e sedes rurais; e corpos d'água. A partir deste mesmo arquivo e composição, foram delimitadas áreas core (regiões de interesse -ROI) para cada uma das classes, de forma visual, sendo gerado um arquivo vetorial com estas delimitações. A ferramenta Creates Signatures, ao combinar o arquivo de áreas core (vetorial) com o arquivo de empilhamento de bandas (raster), gera um arquivo gsg., referente à assinatura espectral de cada uso (amostras de treinamento), a ser empregado na classificação supervisionada.

Para o mapeamento temático das classes de uso e cobertura do solo aplicou-se uma classificação supervisionada, pelo método de classificação por probabilidade máxima (Maximum Likelihood Classification). Este algoritmo de classificação, paramétrico, estima a variância e a covariância dos padrões espectrais das amostras de treinamento e assim, define a relação de semelhança entre os valores, pixels, que seguem esse mesmo padrão nas bandas multiespectrais, agrupando-os em uma mesma classe (ANDRADE et. al., 2014; ESRI, 2016). A classificação foi realizada a partir da ferramenta aximumLikelihoodClassification, do soft-ware ArcGIS 10.5.

\subsection{Superfície e gráfico de tendência}

Para analisar a tendência espacial da variável capacidade específica foram gerados uma superfície e um gráfico de tendência para esta variável. A superfície de tendência resulta numa superfície contínua que representa os padrões espaciais em uma superfície sobre a área de interesse (ESRI, 2016). Já o gráfico de tendência auxilia na identificação de tendências e padrões no conjunto de dados, fornecendo uma perspectiva tridimensional dos mesmos, em que as localizações dos pontos de amostragem são plotadas no eixo $\mathrm{X}$ e Y, e acima de cada ponto da amostra, o valor é dado pela altura de uma coluna na dimensão Z (ESRI, 2016). A superfície de tendência foi gerada a partir da ferramenta Trend, disponível na extensão Spatial Analyst Tools do ArcGIS 10.5, sendo empregado um polinômio de primeira ordem (linear). $\mathrm{O}$ gráfico de tendência foi confeccionado por meio da ferramenta Trend analysis.

\subsection{Mapa de Favorabilidade hidrogeológica por lógica Fuzzy}

O mapa de favorabilidade hidrogeológica foi gerado a partir da combinação dos mapas referentes à: estrutura - densidade de lineamentos; geomorfologia densidade de drenagem, clinometria e forma do terreno (VALERIANO et al., 2010); e litologia. A escolha destas variáveis foi pautada em (SMERDON et al., 2009; SOUZA FILHO et al., 2010; OIKONOMIDIS et al., 2015; OH et al., 2011) e à disponibilidade destes dados, em média escala, para a área.

De acordo com Ferreira et al. (2015), a maioria dos algoritmos empregados na combinação de mapas aplicam regras de decisão booleanas na definição dos limites das classes do mapa resultante. Todavia, os autores salientam que grande parte das variáveis ambientais não apresentam limites rígidos, e perdem muito de suas complexidades naturais quando mapeadas de acordo com a lógica de decisão booleana. Como alternativa, os autores recomendam o emprego de métodos de classificação contínua, em que os valores das variáveis ambientais são apresentados em uma mesma escala de valores, sendo a lógica fuzzy (ZADEH, 1965) uma alternativa para padronizar valores de variáveis.

Seguindo estas premissas, os valores originais dos mapas de densidade de lineamentos (DL), densidade de drenagem (DD) e declividade (DEC) foram convertidos em valores fuzzy pertencentes ao intervalo [0,1], sendo utilizada como função de afinidade a função linear crescente. Já para os mapas qualitativos, forma do terreno (FT) e litologia (LITO), foram atribuídos valores 
dentro de um intervalo de 0 a 1 , para cada uma das classes do mapa.

Os pesos atribuídos às variáveis utilizadas foram adaptados de Madrucci et al. (2008), os quais foram definidos a partir dos valores de capacidade específica para cada unidade fisiográfica na região. Para forma do terreno (VALERIANO et al., 2010) foram aplicados valores de 1 a 9 para as nove classes. De acordo com Valeriano (2008), terrenos com curvatura convergente-côncava tendem a concentrar o fluxo e acúmulo de água, enquanto que terrenos com curvatura divergente-convexa apresentam máxima dispersão do escoamento, e menor infiltração. Assim, foi atribuído valor nove para a classe convergente-côncava e valor 1 para classe divergente-convexa. Para as demais classes, foram atribuídos valores de oito a dois, respectivamente. Posteriormente, estes valores foram convertidos em valores fuzzy.

A favorabilidade hidrogeológica $(\mathrm{FH})$ foi calculada a partir da soma ponderada dos valores fuzzy dos mapas das variáveis empregadas, conforme Equação 1:

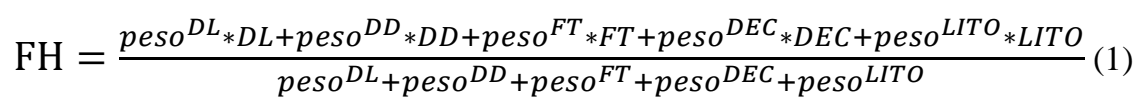

Os pesos atribuídos a cada variável foi baseado em Madrucci et al. (2008): DL = 0,4183; peso $\mathrm{LITO}=0,2079$; peso $\mathrm{FT}=$ 0,1189 ; peso $\mathrm{DEC}=0,0235$; e peso $\mathrm{DD}=$ 0,0235 .

Madrucci et al. (2008) definiu os pesos a partir da correlação entre a capacidade específica dos poços em distintas configurações da paisagem, confrontando estes pelo teste estatístico de comparação pareada. Este teste avalia quais configurações da paisagem resultam em maiores capacidades específicas na área, atribuindo pesos maiores a características que possuem maior correspondência com a produtividade nos diferentes poços tubulares. Para escolha das variáveis empregadas neste estudo, foram considerados os elementos de maior influência no potencial hidrogeológico na área para compor a Equação 1.

Junto aos mapas, foram plotados dados de 78 poços tubulares já instalados, com objetivo de destacar as áreas de perfuração comumente escolhidas para explotação deste recurso. Os dados originados foram utilizados para avaliação e discussão das características fisiográficas que mais afetam a favorabilidade hidrogeológica na área.

\section{RESULTADOS E DISCUSSÃO}

Os aquíferos da área possuem porosidade secundária, caracterizada no local por estruturas tectônicas, relacionadas a zonas de fraqueza das rochas. Estas zonas, foram reativadas e fraturadas em diferentes processos tectônicos, gerando uma tendência principal de lineamentos de direção NE-SW e tendências associadas a E-W e NW (Figura 6), como pode ser observado pela Falha de Monte Sião (Figura 3). As áreas mais afetadas por estes eventos, possuem naturalmente maior favorabilidade hidrogeológica, visto as maiores densidades de fraturas (lineamentos).

Junto às feições estruturais, a litologia possui destaque no condicionamento do fluxo hidrogeológico da área, tanto pela ductibilidade e ruptibilidade, que favoreceu ou dificultou o fraturamento das mesmas, quanto pela origem de sedimentos bem selecionados que se depositaram nas áreas mais baixas, criando grandes pacotes de colúvios, que alimentam os aquíferos locais. Assim, a maior favorabilidade hidrogeológica situa-se ao longo da direção NE-SW, nas áreas cortadas pela falha de Monte Sião.

As áreas de maior favorabilidade (Figura 5), estão, portanto, localizadas na região do Complexo Itapira, onde o grau de metamorfismo é mais baixo que o das rochas do Grupo Amparo, o que levou à formação de litotipos friáveis, como quartzitos. Esta característica, somada aos múltiplos ciclos cataclásticos e metamórficos aos quais as rochas do Grupo Itapira foram submetidas, fez com que, neste domínio, o fraturamento fosse 
mais pronunciado (YOSHINAGA, 1990; HASUI, 2010). Além disto, o material arenoso de maior permeabilidade, gerado da alteração dos gnaisses e quartzitos do Complexo Itapira, pode influir na produtividade dos poços, pois conduz a água com maior eficiência quando comparado ao material argiloso produzido pelo migmatito (YOSHINAGA, 1990).

As áreas de menor favorabilidade (Figura 5) e consequentemente menor quantidade de poços, estão localizadas na região litológica do Complexo Amparo e migmatitos do Complexo Itapira (Figura 3) visto que o processo histórico de ocupação se deu em função das reservas hidrogeológicas. As rochas do Complexo Amparo são consideradas associações litológicas de origem arqueana. Segundo ALMEIDA e HASUI (1984) e ARTUR (1988), estas rochas são essencialmente ortoderivadas, sendo consideradas o embasamento do Grupo ou Complexo Itapira, e sofreram deformação essencialmente dúctil, o que resulta em menor porosidade secundária. Além disto, a partir da ação do intemperismo, estas rochas geram sedimentos finos e impermeáveis que tendem a impermeabilizar as fraturas.

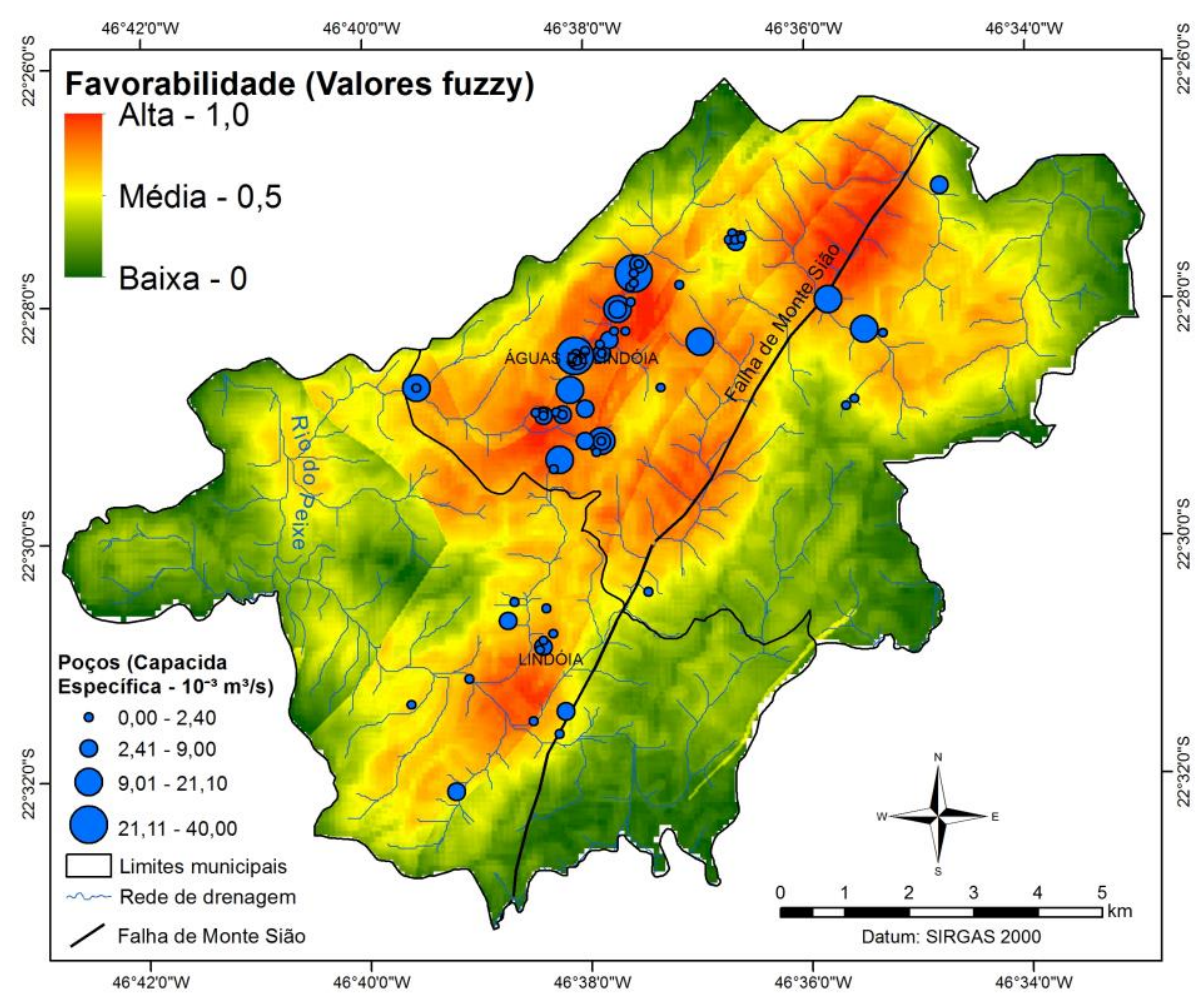

Figura 5 - Mapa de Favorabilidade Hidrogeológica Figure 5 - Hydrogeological Favorability Map

É possível distinguir três feições geomorfológicas principais na área: conjunto de serras orientadas no sentido sul noroeste, cortando Lindóia e Águas de Lindóia; planície deposicional, no nível de base local às margens do Rio do Peixe no Município de Lindoia; e colinas amplas, localizadas a oeste do município de Águas de Lindóia (Figuras 2a e 3). De tal modo, as feições geomórficas de serra e de planície deposicional possuem características que influenciam a hidrodinâmica na área. A declividade tem papel importante no processo de infiltração das águas subterrâneas locais, visto sua capacidade de controlar o escoamento superficial e a infiltração pela aceleração ou atenuação dos fluxos hidrossedimentológicos. As áreas de maior declividade, quando associados às serras, favorecem a dinâmica subterrânea da água. Já nas planícies deposicionais, ocorre o oposto, isto é, as baixas declividades aumentam a 
favorabilidade hidrogeológica. De tal modo, o mapa de favorabilidade (Figura 5) mostrou respostas similares à produtividade dos poços tubulares em todas as classes clinométricas, o que justifica seu baixo peso no modelo.

A combinação dos efeitos intempéricos, combinados à ação morfodinâmica ocorrida desde o Neógeno, tem por vezes potencializado e retrabalhado áreas afetadas por eventos estruturais de ciclos geológicos anteriores. De acordo com as Figuras 6 e 7b, as áreas à oeste da Falha de Monte Sião, possuem uma alta densidade de lineamentos e drenagens, decorrente das características geológicas da área. Isto resultou em uma grande dissecação da paisagem, com vales e drenagens encaixadas nos lineamentos, dobras e falhas, e acúmulo de aluvião nos níveis de base locais (Figuras 2a e 3).

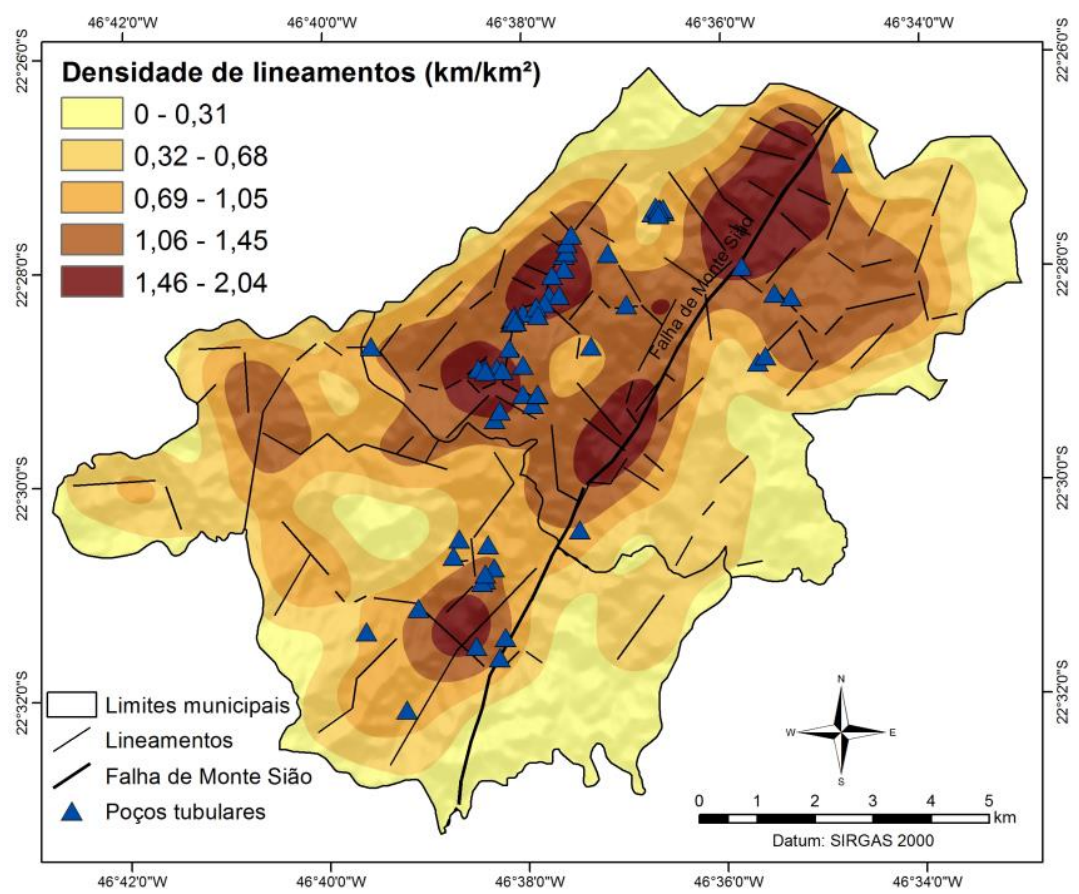

Figura 6 - Mapa de densidade de lineamentos

Figure 6 - Lineaments density map

Os poços tubulares estão localizados principalmente nas áreas de alta densidade de lineamentos e ou drenagem (Figuras 6 e 7a), assim como, nas áreas de aluvião (Figura 3). Segundo o critério do riacho fenda, as drenagens em áreas cristalinas ocorrem no fraturamento das rochas, o que pode explicar a similaridade entre a densidade de lineamentos da Figura 6 e densidade de drenagens da Figura 7a, situação que favorece o potencial hidrogeológico.

Por último, o manto de intemperismo influencia a capacidade produtiva dos poços visto que condicionam as formas das vertentes, que por sua vez tendem a facilitar ou dificultar a infiltração de acordo com suas formas: côncava, convexa, retilínea e mistas. Deve-se destacar que nas áreas geomórficas de colinas amplas, dominadas pelo Complexo Amparo, há predominância de vertentes convexas divergentes, que dissipam a água e reduzem a infiltração, e na região de serras localizadas predominantemente no Complexo Itapira há predominância de vertentes côncavas convergentes, que concentram a água e aumentam a infiltração, já nas áreas de planícies deposicionais, dominam as vertentes côncavas planares conforme modelos da Figura 4. 

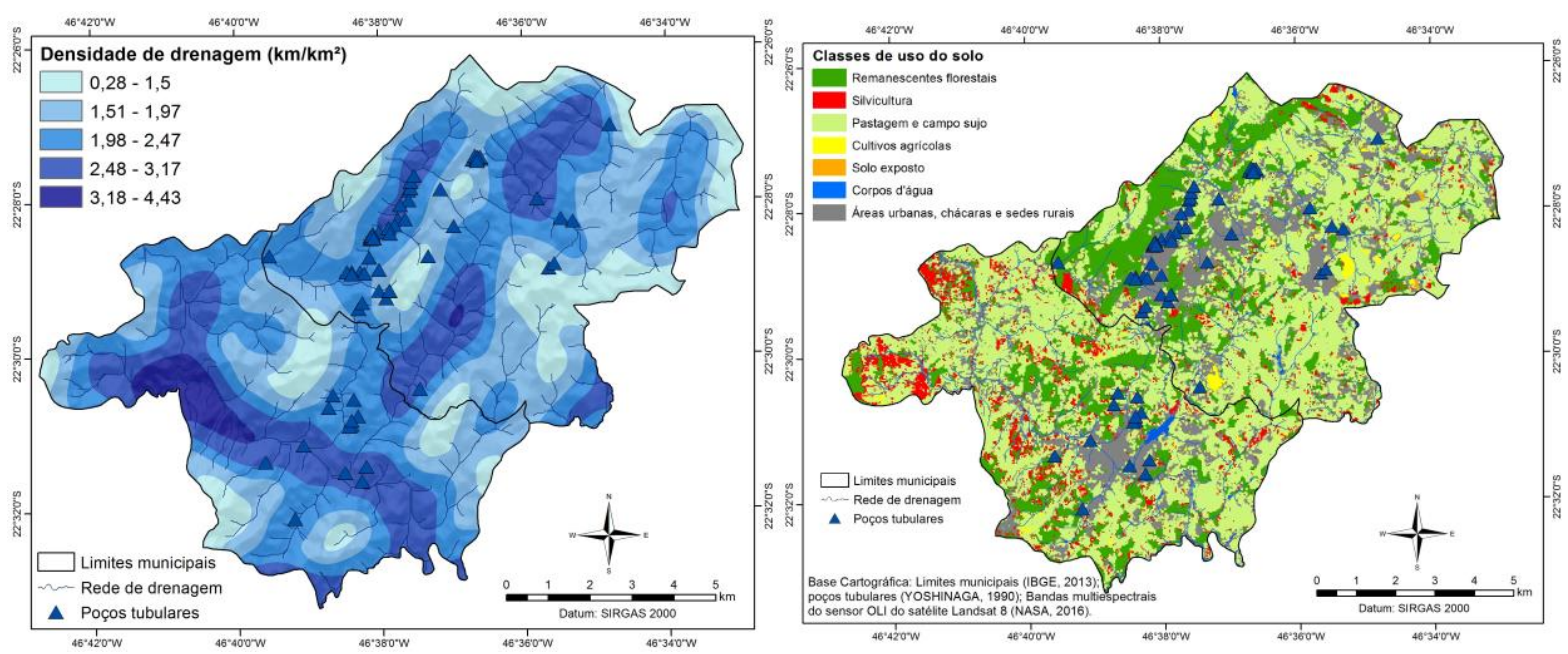

Figura 7 -; (a) Mapa de densidade de drenagem; (b) Mapa de uso e cobertura do solo

Figure 7 - (a) Density map of drainage; (b) Use map and land cover

Deve-se ressaltar que as áreas planas como as planícies deposicionais (Figuras $2 \mathrm{a}$ e 3), como no caso do município de Lindóia, oferecem facilidades à ocupação tanto urbana quanto agropastoril, visto a facilidade em ocupar, construir edificações e mecanizar as lavouras, devido aos menores declives, além da proximidade de recursos hídricos. Porém, estes são locais mais suscetíveis à contaminação das águas, devido ao nível raso de água subterrânea e aos sedimentos aluvionares permeáveis.

No caso destes municípios, os núcleos urbanos Figura $7 \mathrm{~b}$ estão localizados nas áreas menos declivosas (Figura 2b). As áreas de maiores declives possuem maior quantidade de vegetação nativa preservada, enquanto as áreas de menores declives, principalmente na borda leste dos municípios, possuem grandes terrenos ocupados pela agropecuária (Figura 7b). As áreas com maior densidade de poços estão localizadas dentro ou próximas às áreas urbanas. Todavia, as vertentes que alimentam estes poços tubulares possuem alta taxa de cobertura por mata nativa (Figura $7 \mathrm{~b}$ ), visto que se localizam em áreas declivosas, com ocupação urbana e agropecuária restrita às várzeas e alguns topos de morros. Isto pode contribuir para a manutenção da qualidade das águas nestes locais, além de permitir uma infiltração mais constante ao longo do tempo, o que pode reduzir a variação do nível piezométrico dos poços tubulares, assim como conservar o potencial produtivo dos mesmos
(UNESCO, 2015).

As áreas de baixa favorabilidade, localizadas principalmente na porção leste dos municípios, possuem como características comuns os litotipos compostos por migmatitos do Complexo Amparo (Figura 3) com baixo potencial hidrogeológico, além de menor densidade de lineamentos e de drenagens (Figuras 6 e 7a) e geomorfologia com predomínio de colinas amplas. A baixa favorabilidade pode ainda estar relacionada aos relevos mais planos, que tendem a gerar solos mais desenvolvidos e argilosos, menos permeáveis, gerado pelas rochas migmatíticas e graníticas. Neste tipo de terreno, somada a todas as características até aqui discutidas, ocorre também a eluviação dos sedimentos mais finos dos primeiros horizontes dos solos, que são carreados para as áreas mais profundas do manto de intemperismo, inclusive sendo depositados nas fraturas das rochas (FETTER, 1994). Isto pode levar à redução da condutividade hidráulica, dentro das fraturas, reduzindo a favorabilidade hidrogeológica.

A superfície de tendência criada a partir da capacidade específica dos poços tubulares (Figura 8a), evidencia um padrão espacial dominante, que indica um aumento da tendência de ocorrência de maiores capacidades específicas de sul para norte e de leste para oeste, confirmando os padrões do mapeamento da favorabilidade apresentado na Figura 5. 

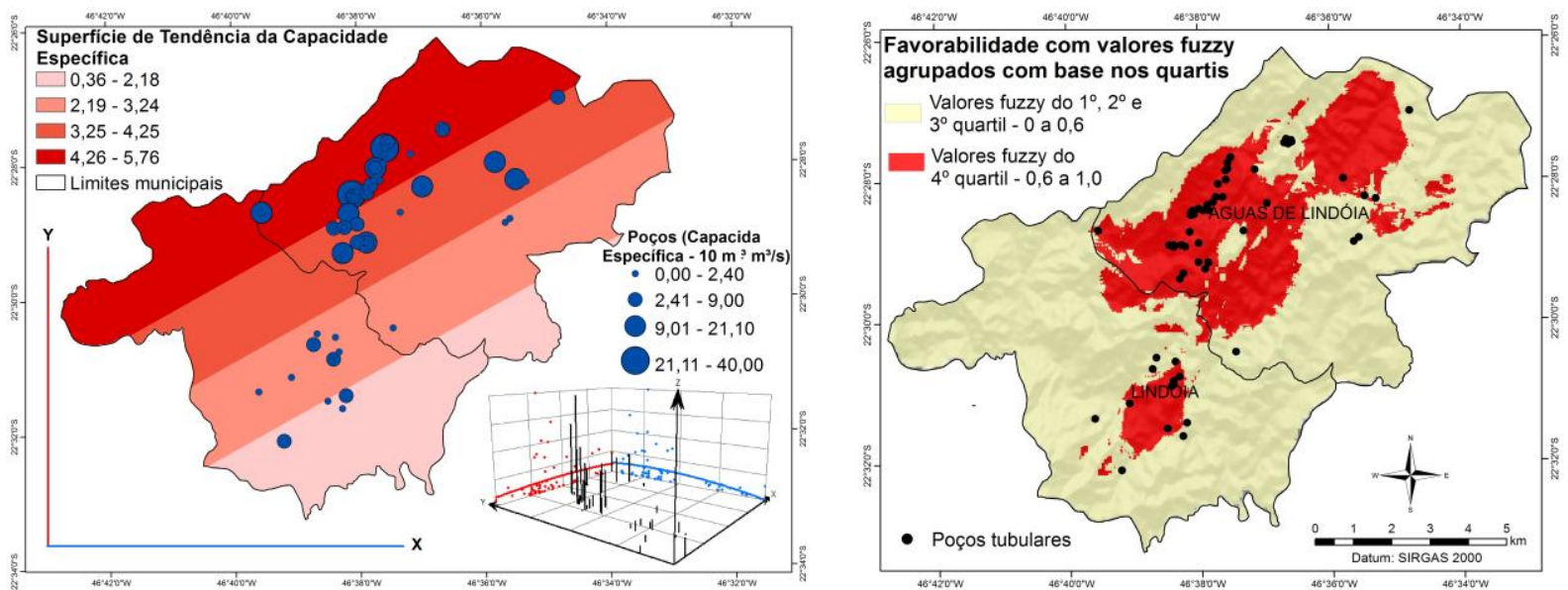

Figura 8 - (a) Mapa e gráfico da superfície de tendência da Capacidade específica; (b) Mapa de Favorabilidade Hidrogeológica

Figure 8 - (a) Map and graph of the trend surface of the specific; (b) Capacity Hydrogeological Favorability Map

$\mathrm{Na}$ Figura 8b, o mapa de favorabilidade hidrogeológica foi classificado pelo método dos quartis. Na primeira classe foram agrupados os valores fuzzy correspondentes aos quartis 1,2 e 3 (valores fuzzy de 0 a 0,6 ), que juntos representam $75 \%$ da área de estudo. A segunda classe é referente aos valores fuzzy do $4^{\circ}$ quartil, referente aos valores fuzzy de 0,6 a 1,0. Embora os valores fuzzy desta última classe ocorram em apenas $25 \%$ da área de estudo, 54 dos 78 poços tubulares já perfurados $(69,23 \%)$ estão localizados nestas áreas. Vale destacar, que os poços tubulares situam-se em áreas historicamente reconhecidas como de boa favorabilidade, evidenciando assim o alto desempenho do modelo aplicado neste trabalho.

\section{CONCLUSÕES}

O uso de lógica Fuzzy para avaliação da favorabilidade hidrogeológica apresentou resultados satisfatórios.

A porção a oeste da Falha de Monte Sião possui melhor potencial hidrogeológico, pela presença de litotipos friáveis como o quartzito, do Complexo Itapira, o que resultou em alta densidade de fraturas, relevo irregular e preservação das matas.

O município de Águas de Lindóia possui favorabilidade hidrogeológica muito maior que o de Lindóia, devido à maior densidade de fraturas, juntas ou desconti- nuidades derivadas de deformação rúptil, todavia ambos os municípios apresentam boa favorabilidade hidrogeológica.

$\mathrm{Na}$ porção sudoeste e na borda leste ocorrem os menores valores de favorabilidade, resultado dos tipos litológicos do Complexo Amparo, que dificultam o fraturamento, com menores amplitudes altimétrica e relevo mais suave, o que facilitou também a supressão das matas nativas.

\section{AGRADECIMENTOS}

À CAPES, FAPESP e à colaboração da Dra. Vanessa Madrucci. Às contribuições de revisores anônimos da Revista Aguas Subterrâneas - ABAS.

\section{REFERÊNCIAS}

ABDALLA, F. Mapping of groundwater prospective zones using remote sensing and GIS techniques: A case study from the Central Eastern Desert, Egypt. Journal of African Earth Sciences, v.70, p. 8-17, julho, 2012.

ALMEIDA F.F.M.; HASUI Y. O Pré-cambriano no Brasil. 1ed. Brasil Edgard Blucher. 1984. $378 p$.

ARTUR, A.C. Evolução policíclica da infraestrutura da porção sul do Estado de Minas Gerais e Regiões adjacentes do Estado 
de São Paulo. Tese (Doutorado)- IG - USP, 1988. 231p.

CÂMARA G., CARVALHO, M.S. Análise de processos pontuais. In: Druck, S.; Carvalho, M.S.; Câmara, G.; Monteiro, A.V.M. (eds) Análise espacial de dados geográficos. Brasília, Embrapa, 2004.

CHRISTOFOLETTI, A. Modelagem de sistemas ambientais. São Paulo: Edgard Blucher, 1999. $188 \mathrm{p}$.

DNPM, Departamento Nacional de Produção Mineral. Sumário mineral. Brasília, DNPM, 2013. 137p

DAEE, Departamento de Águas e Energia Elétrica. Base cartográfica digital, escala 1:50.000 - Projeto GISAT. São Paulo: DAEE, (2008).

DAEE, Departamento de Águas e Energia Elétrica 1981. Estudo de águas subterrâneas. Região Administrativa 5. Campinas, v. 1, 343 pp.

ELBEIH, S. F. An overview of integrated remote sensing and GIS for groundwater mapping in Egypt. Ain Shams Engineering Journal, v. 6, n. 1, p. 1-15, março, 2015.

ESRI - Environmental Systems Research Institute (2011). Help. Disponível em: http://help.arcgis.com/. Acesso em: 03/04/2016.

FERREIRA, M.C.; GAROFALO, D.T.; ERREIRA, M.M. Mapeamento do risco de ravinamento na área de proteção ambiental Fernão Dias, sudeste do Brasil, a partir de lógica de decisão Fuzzy. Territorium - Revista Portuguesa de Riscos, v. 22, p. 77-86, 2015.

FETTER, C.W. Applied hydrogeology. McMillan College Publ. Co. New York, 1994. $680 \mathrm{p}$

FEITOSA F.A.C. (Ed) Hidrogeologia: conceitos e aplicações. 3. ed. Rio de Janeiro, CPRM LABHID, 2008. 812p

HASUI, Y. A Grande Colisão Pré-Cambriana do Sudeste Brasileiro e a Estruturação Regional. Geociências, São Paulo, v. 29, n. 2, p. 141-169, 2010
HIRATA, R. et al. Água Subterrânea: reserva estratégica ou emergencial. In Bicudo, C. E. M. et al. (orgs.). Águas no Brasil: Análises estratégicas. Academia Brasileira de Ciência, São Paulo. 2010. p. 149-161.

HUGGETT, R.J. Systems Analysis in Geography. Clarendon Press,Oxford, 1980, 208p.

MADRUCCI V.; TAIOLI F.; Araújo C.C. Groundwater favorability map using GIS multicriteria data analysis on crystalline terrain, São Paulo State, Brazil. Journal of Hydrology, v. 357, p. 153-173, 2008.

OH, H.; KIM Y. S.; CHOI, J. K.; PARK, E.; LEE, S. GIS mapping of regional probabilistic groundwater potential in the area of Pohang City, Korea. Journal of Hydrology, v. 399, n. 3-4, p. 158-172, Março, 2011.

OIKONOMIDIS, D.; DIMOGIANNI, S.; KAZAKIS, N.; VOUDOURIS, K. A GIS/Remote Sensing-based methodology for groundwater potentiality assessment in Tirnavos area, Greece. Journal of Hydrology, v.525, p. 197-208, junho, 2015

RAHMATI, O.; MELESSE, A. M. Application of Dempster-Shafer theory, spatial analysis and remote sensing for groundwater potentiality and nitrate pollution analysis in the semi-arid region of Khuzestan, Iran. Science of The Total Environment, v. 568, p. 1110-112315, outubro, 2016.

SMERDON B.D.; ALLEN D.M.; GRASBY S.E.; Berg M.A. An approach for predicting groundwater recharge in mountainous watersheds. Journal of Hydrology, v. 365, p. 156-172, 2009.

SPAROVEK, G.; VAN LIER, Q.J.; NETO, D.D. Computer assisted Köppen climate classification: a case study for Brazil. International Journal of Climatology, Chichester, v. 27, n. 2, p.257-266, 2007.

SOARES, P.C.; FIORI, A. P. Lógica e Sistemática na análise interpretação de fotografias aéreas em geologia. Noticiário Geomorfológica, 1976. P.107-121.

SOSMA - FUNDAÇÃO SOS MATA ATLANTICA; INSTITUTO NACIONAL DE PESQUISAS ESPACIAIS - INPE. Atlas dos 
Municípios da Mata Atlântica - período 20112012, Anexo 1. São Paulo, INPE, 2013. 100p.

SOUZA FILHO O.A.; MOREIRA SILVA A.M.; REMACRE A.Z.; SANCEVERO S.S.; MCCAFFERTY A.E.; PERROTTA M.M. Using helicopter electromagnetic data to predict groundwater quality in fractured crystalline bedrock in a semi-arid region, Northeast Brazil. Hydrogeology Journal, v. 18, p. 905-916, 2010.

TUNDISI, J.G. Recursos hídricos no Brasil: problemas, desafios e estratégias para o futuro. Academia Brasileira de Ciências, Rio de Janeiro, 2014. 90 p.

UNESCO, United Nations Educational, Scientific and Cultural Organization. World Water Development Report: Water fora a sustainable world. UNESCO, Paris. 2015. 139p.
VALERIANO, M.M. Dados topográficos. In: Florenzano, T. G. Geomorfologia: conceitos e tecnologias atuais. São Paulo: Oficina de Texto, p. 72-104, 2008.

VALERIANO, M.M.; ALBUQUERQUE, P.C.G. Topodata: processamento dos dados SRTM. São José dos Campos: INPE, 2010.

YOSHINAGA S.P. Estudos hidrogeológicos, hidrogeoquímicos $\mathrm{e}$ isotópicos das águas minerais e termais de Águas de Lindóia e Lindóia, SP. Dissertação (Mestrado) Universidade de São Paulo, São Paulo, 1990. 113 p. 